\title{
Importance and Assessment of Quality of Life in Symptomatic Permanent Atrial Fibrillation: Patient Focus Groups from the RATE-AF Trial
}

\author{
Jacqueline Jones $^{a} \quad$ Mary Stanbury $^{a}$ Sandra Haynes $^{a}$ Karina V. Bunting ${ }^{b, c}$ \\ Trudie Lobban $^{d}$ A. John Camm ${ }^{e}$ Melanie J. Calvert ${ }^{f-h}$ Dipak Kotechab, c, g \\ on behalf of the RAte control Therapy Evaluation in permanent Atrial Fibrillation
}

(RATE-AF) trial group

\begin{abstract}
a Patient and Public Involvement Team, RATE-AF trial, Birmingham, UK; ${ }^{\mathrm{b}}$ Institute of Cardiovascular Sciences, University of Birmingham, Birmingham, UK; ${ }^{C}$ University Hospitals Birmingham NHS Foundation Trust, Birmingham,

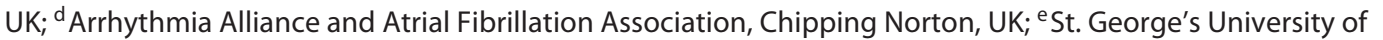
London, London, UK; ' Institute of Applied Health Research \& National Institute for Health Research Biomedical Research Centre, University of Birmingham, Birmingham, UK; ${ }^{9}$ Centre for Patient Reported Outcomes Research,

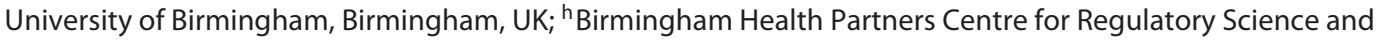
Innovation, University of Birmingham, Birmingham, UK
\end{abstract}

\section{Keywords}

Atrial fibrillation · Quality of life · Focus group · Qualitative · Assessment

\begin{abstract}
Aims: To establish the extent and impact of symptoms in patients with atrial fibrillation (AF), the importance of different aspects of quality of life (QoL), and how we should assess wellbeing. Methods: Focus groups of patients with symptomatic permanent AF in a trial of heart rate control; the RATE-AF trial randomised 160 patients aged $\geq 60$ years with permanent AF and at least NYHA class II dyspnoea to either digoxin or beta-blockers. Patient and public representatives led the focus groups and performed all data acquisition and analysis, using thematic approaches to interpret patient views about QoL and its measurement. Results: Substantial impairment of health-related QoL was noted in 160 trial patients, with impact on all domains apart from mental health. Eight women and 11 men aged 61-87 years participated in the focus groups. Common themes were a lack of informa-
\end{abstract}

karger@karger.com www.karger.com/crd

Karger $\frac{1}{\%}$

GOPEN ACCESS
(C) 2020 The Author(s)

Published by S. Karger AG, Basel

This article is licensed under the Creative Commons Attribution 4.0 International License (CC BY) (http://www.karger.com/Services/ OpenAccessLicense). Usage, derivative works and distribution are permitted provided that proper credit is given to the author and the original publisher. tion from healthcare professionals about AF, a lack of focus on QoL in consultations, and a sense of frustration, isolation, and reduced confidence. There was marked variability in symptoms in individual patients, with some describing severe impact on activities of daily living, and profound interaction with comorbidities such as arthritis. Day-to-day variation in QoL and difficulty in attributing symptom burden to $\mathrm{AF}$ or other comorbidities led to challenges in questionnaire completion. Consensus was reached that collecting both general and AF-specific QoL would be useful in routine practice, along with participation in peer support, which was empowering for the patients. Conclusions: The impact of comorbidities is poorly appreciated in the context of AF, with considerable variability in QoL that requires both generic and AF-specific assessment. Improvement in QoL should direct the appraisal, and reappraisal, of treatment decisions for patients with permanent AF.

(C) 2020 The Author(s)

Published by S. Karger AG, Basel

Jacqueline Jones and Mary Stanbury are joint first authors.
Dipak Kotecha, MBChB, MRCP, PhD, MSc, FESC, FHEA

University of Birmingham Institute of Cardiovascular Sciences

Medical School, Vincent Drive

Birmingham B15 2TT (UK)

d.kotecha@bham.ac.uk 


\section{Introduction}

Atrial fibrillation (AF) is a major burden on patients and healthcare services. These effects are projected to increase exponentially as our communities grow older and the incidence of AF in older people increases [1]. Although adverse outcomes in AF such as stroke rightly receive attention from clinicians due to their preventable nature, poor patient quality of life (QoL) often lacks consideration in clinical practice, despite also being amenable to treatment.

Patients with AF have significantly poorer health-related QoL [2], which includes comparison with both healthy individuals and those with other cardiovascular diseases [3]. This has been attributed to the variety of symptoms that AF patients can suffer, including lethargy, palpitations, dyspnoea, sleeping difficulties, chest discomfort, and psychosocial distress, as well as anxiety related to treatments and potential complications [4]. Although QoL is significantly related to mortality, AF-related symptoms do not necessarily track with clinical outcomes such as stroke, heart failure, or myocardial infarction, making extraction of QoL information important for routine clinical management [5]. The majority of published studies on QoL in AF relate to the response to rhythm control therapies such as antiarrhythmic drugs or ablation. In contrast, patients with permanent $\mathrm{AF}$ have even worse QoL [6], account for around $50 \%$ of all patients, and yet we lack an adequate description of underlying factors [7].

The current unknowns about QoL in patients with permanent AF limit the scope of how effective clinicians can be in addressing patient concerns. We designed a qualitative study, led by a Patient and Public Involvement (PPI) team, and embedded within a clinical trial; the RAte control Therapy Evaluation in permanent Atrial Fibrillation (RATE-AF) trial [8]. Our aim was to explore 3 broad domains: (1) The perspective of patients on core components of health-related QoL and how this is influenced by AF; (2) The measurement of QoL in AF and what tools were felt useful by patients to measure the response to treatment; and (3) Whether QoL was an important outcome that clinicians should address.

\section{Methods}

This mixed methods study was part of the RATE-AF trial programme, a prospective, open-label, blinded endpoint, randomised controlled trial of 160 patients with symptomatic permanent AF. The trial is the first to directly compare longer-term heart rate con- trol using digoxin and beta-blocker therapy in this patient group (clinicaltrials.gov: NCT02391337, ISRCTN: 95259705, and EudraCT: 2015-005043-13). The rationale and design of the study have previously been described [7]; in brief, the trial was embedded within the UK National Health Service (NHS), with minimal selection criteria to reflect routine clinical care. Patients were aged 60 years or older, with permanent AF, in need of rate control, and breathlessness equivalent to at least New York Heart Association (NYHA) class II. As per guidelines, permanent AF was characterised as a physician decision for rate control with no plans for cardioversion, antiarrhythmic drugs, or ablation [9]. We only excluded patients with either clear requirements or contraindications for either drug, for example myocardial infarction in the last 6 months, a history of severe bronchospasm, bradycardia, or previous intolerance. The RATE-AF trial and the qualitative aspects were sponsored by the University of Birmingham and funded by the UK National Institute for Health Research (NIHR).

\section{Patient and Public Involvement}

A team of 3 PPI members helped to design and manage the trial, including positions on the Trial Steering Committee. The design of the focus groups was led by J.J. and M.S. from the PPI team, with the support of cardiology, patient-reported outcomes research, and qualitative research teams at the University of Birmingham.

\section{Participant Recruitment and Data Collection}

Patients for the RATE-AF trial were recruited from referrals to 3 hospital sites in Birmingham (Queen Elizabeth Hospital, City Hospital, and Heartlands Hospital), and also directly from General Practices across the West Midlands region in the UK. As part of the consent procedure, all participants were asked if they could be contacted to contribute to the focus groups. From this cohort, 20 patients were consecutively invited to attend based on completion of all drug uptitration at that time (i.e., beyond the first 2 months of their trial participation), purposely sampled by gender and randomised group. No clinical variables were used to decide on focus group composition, but the participants had to be able to attend on the specified date ( 5 patients refused/were unable to attend on the date and were replaced with the next available patients). One patient who accepted was unable to attend on the day due to illness. Focus groups were held at the NIHR/Wellcome Trust Clinical Research Facility at the Queen Elizabeth Hospital Birmingham in 2019 and split into 2 meetings for each arm of the trial. The first meeting focused on building rapport within the group and the impact of AF on their lives, with the second meeting focused on assessment and tools to measure that impact. Each meeting lasted approximately $2.5 \mathrm{~h}$ separated by two weeks (with a maximum of 10 participants in each meeting). Focus groups were led by the patient and public representatives (J.J. and M.S.) with D.K. also in attendance to address any medical issues.

\section{Reimbursement}

Every patient received a fixed sum of GBP 50 for their contribution to each focus group, in addition to appropriate compensation for travel and subsistence costs. PPI members received funding according to NIHR INVOLVE guidance (https:// www.invo.org.uk/). There was no industry funding for any part of this trial. 


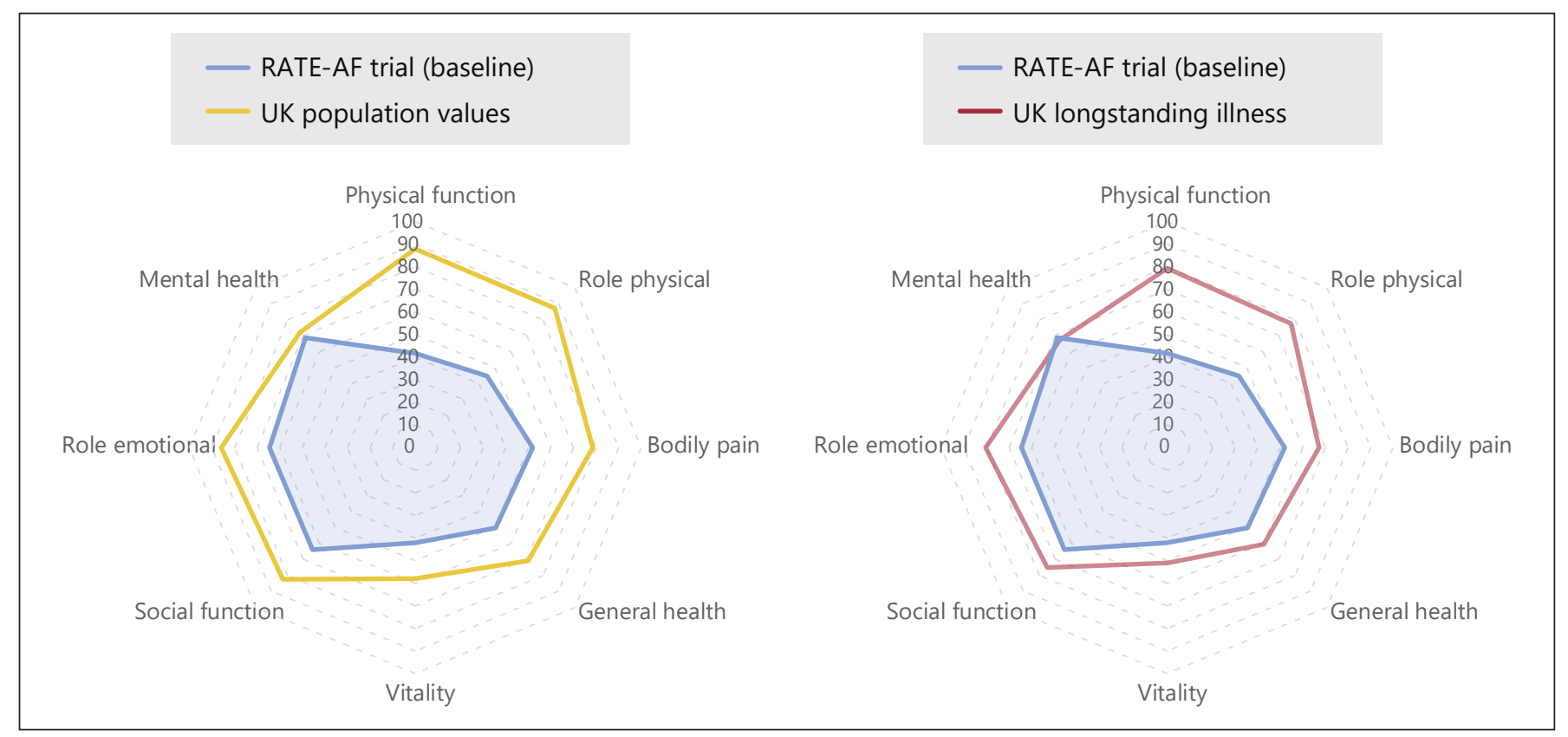

Fig. 1. Comparative quality of life scores. SF36 quality of life scores in 160 RATE-AF patients. Left: Values compared to the UK population average from the OHLS-III social survey in 8,889 participants. Right: Comparison with the $40 \%$ of respondents declaring a longstanding illness in OHLS-III. Higher scores indicate better quality of life; all components demonstrated statistically worse quality of life in RATE-AF patients $(p<0.0001)$, except for mental health $(p=0.49)$.

\section{QoL Tools}

Three validated QoL questionnaires were used in the RATE-AF trial [7]. AF-specific QoL was assessed using the Atrial Fibrillation Effect on QualiTy-of-life (AFEQT) questionnaire [10]. Generic QoL was assessed using both the EuroQol EQ-5D-5L questionnaire [11] and the Short Form 36 Health Survey (SF36) [12]. The SF36 survey is comprised of eight domains; normalised UK values were taken from 8,889 respondents of a large-scale social survey, the Third Oxford Health and Lifestyles Survey (OHLS-III), sampled from primary care in the UK [13]. $t$ tests adjusted for unequal variance were used to compare mean values with data from the baseline visit of the RATE-AF trial. All participants of the focus groups had experience of completing all 3 questionnaires on at least 2 occasions during their trial visits. At the end of the first meeting, copies of the questionnaires were also provided to the participants for discussion at the next meeting.

\section{Data Analysis}

A topic guide was developed and finalised by the PPI team prior to the focus groups, and this was used as a roadmap for discussions in each meeting. The topic guide included specific questions relating to the three study domains and corresponding probe questions to explore these issues in more detail (online suppl. file; see www.karger.com/doi/10.1159/000511048 for all online suppl. material). Audio recordings of the meetings were made with the consent of all participants. A professional service transcribed the interviews (clean verbatim), and the transcription was reviewed for consistency and accuracy by J.J. and M.S. The data (recordings and transcripts) were analysed using thematic approaches [14]. To or- ganise the patient comments into the 3 key domains of interest, we developed a set of codes after the authors had familiarised themselves with the content of the transcripts. For the components of health-related QoL in AF, the codes related to any comment on: Physical impact from AF; Emotional impact from AF; Daily life impact from AF; Impact on carers; Interaction with comorbidities; Prior knowledge of AF or lack thereof; and Importance of QoL to the patient. For measurement of QoL in AF: Value of the QoL questionnaire; and Comparison of QoL questionnaires. For the importance of addressing QoL: Treatment expectations; Impact of the trial medications on physical function; and Impact of the trial medications on QoL. An iterative process was performed of coding each transcript (J.J. and M.S.). The codes were compiled in a data spreadsheet with extracted statements given primary codes (main issue raised by the patient in that comment) and secondary codes (where, if required, an additional issue was raised in the same comment). J.J. and M.S. also manually extracted specific quotes from patients that were relevant or particularly significant to the group as a whole or may not have fitted into the specified codes.

\section{Results}

RATE-AF trial data at baseline from 160 patients with symptomatic permanent AF confirmed a substantial reduction in QoL in all domains of the SF36 questionnaire, except for mental health. This was observed 


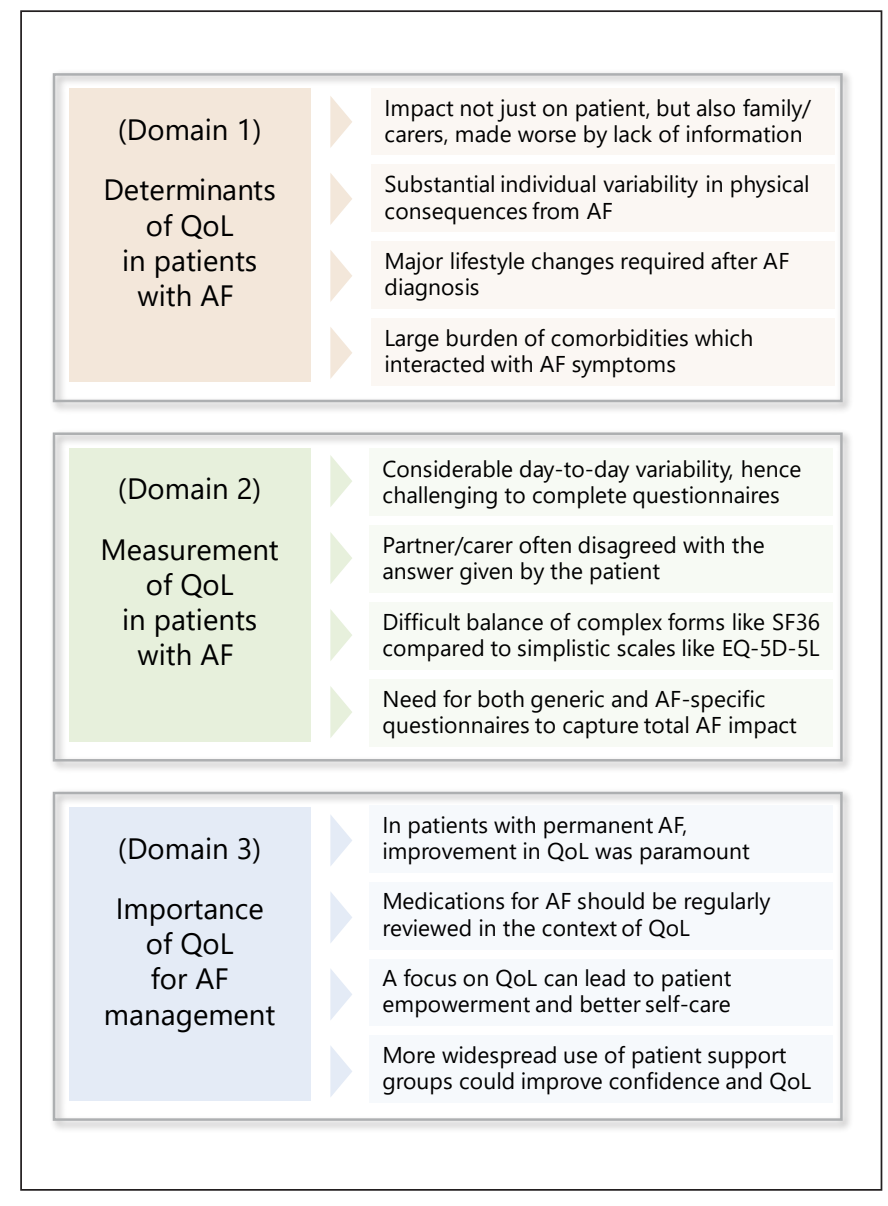

Fig. 2. Summary of RATE-AF focus groups. Key issues raised by patients according to relevant themes. AF, Atrial fibrillation; QoL, Quality of life.

compared to the UK norm, as well as compared to those with a longstanding illness in population survey data (Fig. 1).

Nineteen participants took part in the focus groups, comprising 8 women and 11 men, all from a white British background. Mean age was 74 years (SD 7), with a range of 62-86 years. Patients had been diagnosed with AF for a mean of 5 years, and 10 (53\%) had a known diagnosis of co-existing heart failure or signs of heart failure at baseline. Other common comorbidities were hypertension in 11 patients (58\%), type 2 diabetes in $5(26 \%)$, airways disease in $4(21 \%)$, and previous stroke or transient ischaemic attack in 3 (16\%). The demographics of the focus group participants were all comparable with the main trial population [8]. All patients had completed uptitration of their trial medication ( 10 randomised to digoxin and 9 to beta-blockers) and were on stable dosage with ade-
Does atrial fibrillation (AF) affect a patient's quality of life?

- How severely patients are affected by AF varies a lot

- Other health problems can influence how AF affects each person

- Coping with AF often requires changes in daily living

- AF has an impact on the patient, but also affects their family and carers

How might patients feel because of AF?

- Patients may have different feelings from day to day

- What a patient feels may not agree with what their family or carer sees

- Whether these feelings are due to AF, or other health conditions, is different for every patient

- We need more research to find better ways to measure how patients are feeling

Is it important to know how patients with AF are feeling?

- Patients with AF in this study were keen to improve their quality of life

- It can be useful to monitor how quality of life changes in response to treatment

- Patients monitoring how they feel can have a positive effect on their quality of life

- AF support groups can help patients to feel confident and enjoy a better quality of life

Fig. 3. Summary for patients. Information about atrial fibrillation (AF) for patients can be found at: https://www.bhf.org.uk/informationsupport/conditions/atrial-fibrillation. Patient resources and support are available at: https://www.heartrhythmalliance. org/afa/uk/for-patients.

quate control of heart rate. A summary of key findings, determined by the Patient and Public leads, is presented in Figure 2 and a summary for patients in Figure 3.

\section{Domain 1}

Determinants of QoL in Patients with AF

Key issues raised with regards to determinants of QoL and how AF affects the lives of patients were:

1 There was consistent feedback about a lack of information from healthcare professionals about AF and a lack of focus on QoL in healthcare consultations. This led to a sense of frustration, isolation, and reduced confidence which contributed to the overall impact of AF on patient wellbeing.

2 The impact of AF was not just felt by patients, but also by their primary caregivers and the wider family.

3 There was marked variability in AF symptoms in individual patients, with some describing severe impact on physical capacity and activities of daily living due to breathlessness, fatigue, and dizziness, whereas others had few symptoms. 
Table 1. Determinants of QoL in patients with AF

\begin{tabular}{|c|c|c|}
\hline Impact & Quote & Comments/Context \\
\hline $\begin{array}{l}\text { Emotional impact on } \\
\text { patient and family }\end{array}$ & $\begin{array}{l}\text { "As you say it can be a lonely thing [having AF]; You've got } \\
\text { company round you but even so, you are thinking am I the } \\
\text { only one like this?" } \\
\text { "I'm losing my confidence to go out." } \\
\text { "If you aren't positive you might as well pack up and sit in } \\
\text { your armchair." } \\
\text { "Unfortunately, my partner takes the brunt in the way I } \\
\text { sometimes feel [anger and frustration].” } \\
\text { "I find the most exasperating thing is having to ask for help; } \\
\text { I loathe it." } \\
\text { "I sometimes think I don't go anywhere where I'm more } \\
\text { than half an hour away from [the hospital], because it's } \\
\text { frightening if something does go wrong." }\end{array}$ & $\begin{array}{l}\text { Common feelings were fear and bewilderment at the time of } \\
\text { diagnosis, which persisted. } \\
\text { Consistent theme of inability or reticence to ask questions leading } \\
\text { to a loss of confidence; often not verbalised to their usual } \\
\text { healthcare practitioners. } \\
\text { General feelings of isolation, with a sense of loneliness that was } \\
\text { pervasive despite interaction with family and friends. } \\
\text { Dependency and burden on caregivers was highlighted many } \\
\text { times. } \\
\text { Fear of complications and the unknown was common, and } \\
\text { impacted on overall QoL. }\end{array}$ \\
\hline $\begin{array}{l}\text { Impact on physical } \\
\text { activity }\end{array}$ & $\begin{array}{l}\text { "If I'm out on a walk and come to a hill it gets harder and } \\
\text { harder and I get slower and slower." } \\
\text { "I used to play rugby and cricket, but walking round the } \\
\text { snooker table [is all I can manage] and I don't know } \\
\text { whether that counts [as exercise]." } \\
\text { "I feel a bit of a fraud because I have no symptoms; I walk } \\
2.5 \text { miles every day to get my paper, and I don't just walk, I } \\
\text { pound it." } \\
\text { "Housework and stuff - I can't do what I used to do. When } \\
\text { vacuuming sometimes I stop after five minutes and I'm } \\
\text { breathless and [need to] sit down." } \\
\text { "I can do my housework slowly and everything seems fine." } \\
\text { "My life is so changed following [AF therapy] - I can walk } \\
\text { and I'm a garden fanatic; I'm out there digging and sawing } \\
\text { trees." }\end{array}$ & $\begin{array}{l}\text { There was a diverse range of comments on the impact of AF on } \\
\text { physical capabilities. } \\
\text { The majority of patients felt that their AF had negatively } \\
\text { impacted on physical activity, but a few patients had no apparent } \\
\text { change in their ability; a minority recognised an increase in their } \\
\text { ability to carry out physical activity due to medical therapy for } \\
\text { previously undiagnosed AF. } \\
\text { The uncertainty of not knowing how they would feel on any } \\
\text { given day was frustrating, particularly as causal factors were } \\
\text { difficult to identify (i.e., whether due to AF, comorbidities, the } \\
\text { general aging process, or a combination). } \\
\text { The impact of emotional factors on physical activity was evident, } \\
\text { particularly anxiety around their AF diagnosis, and the effect on } \\
\text { their cardiovascular and general health. }\end{array}$ \\
\hline $\begin{array}{l}\text { Impact on daily living } \\
\text { and wellbeing }\end{array}$ & $\begin{array}{l}\text { "I feel degraded my wife has to shower me." } \\
\text { "I was full of life, but no longer." } \\
\text { "[I am] breathless and have no energy to stand there and do } \\
\text { it [ironing]." } \\
\text { "Previous lifestyle has now completely changed." } \\
\text { "I force myself to do things. You can't just sit in the chair all } \\
\text { day looking out of the window." }\end{array}$ & $\begin{array}{l}\text { For a few patients, there was little change in daily living, but the } \\
\text { majority felt that their AF diagnosis had a major effect on daily } \\
\text { wellbeing. } \\
\text { Living with the variability of symptoms on a daily basis created } \\
\text { uncertainty for patients around being able to plan activities; there } \\
\text { was a sense that on any given day their body would dictate the } \\
\text { amount of activity they were able to undertake. } \\
\text { Asked to rate the impact of AF on their daily life (where } 1 \text { was no } \\
\text { impact and } 10 \text { the greatest impact), the majority gave a score of } 7 \\
\text { or above. } \\
\text { Some patients acknowledged that their previous lifestyle was not } \\
\text { compatible with their current status after the diagnosis of AF; the } \\
\text { realisation that significant changes were required in their daily } \\
\text { planning was found to be extremely hard to accept and to adapt. }\end{array}$ \\
\hline
\end{tabular}

4 In group discussion, the patients concluded that the impact of comorbidities (especially large-joint arthritis) was the most important determinant of the effect of AF on physical activity. There was consistent feedback that the effect and treatment of comorbidities was poorly considered in interactions with healthcare professionals.

5 Adaptation to a new style of living was required after the diagnosis and treatment of $\mathrm{AF}$, and there were considerable emotional impacts.

A summary of quotes from patients relevant to this domain are presented in Table 1.

\section{Domain 2}

Measurement of QoL in Patients with AF

The key points discussed about tools to measure QoL and treatment response were:

1 Most patients found it difficult to complete questionnaires due to considerable day-to-day variation in their AF-related symptoms. There were challenges for questionnaires like EQ-5D-5L (which asks about impact today), as well as SF36 and AFEQT (4-week recall period). 
Table 2. Measurement tools for QoL in AF

\begin{tabular}{|c|c|c|}
\hline Tool & Quote & Comments/Context \\
\hline SF36 & $\begin{array}{l}\text { "Often I felt [my symptoms] fell between two tick boxes." } \\
\text { "When you actually fill it in, it gives you time to think of what you } \\
\text { felt like. It can be the mood you're in." } \\
\text { "My partner coaxed me into answering, and I said do you agree with } \\
\text { what I am saying? She responded with: No, I don't agree with that." } \\
\text { "Pigeonholing [how I feel] into the right box that most accurately } \\
\text { describes how I feel about my AF symptoms is difficult." } \\
\text { "I think if I've got AF and there's a risk of a stroke [so] how can I put } \\
\text { my health down as good?" } \\
\text { "I think there's a lot of duplication... are you worn out? Have you } \\
\text { felt downhearted? Are you full of energy?" }\end{array}$ & $\begin{array}{l}\text { There was a general consensus within the group that a diagnosis } \\
\text { of AF led to symptoms and activity limitation that varied from } \\
\text { day to day, making it challenging to average QoL over a four-week } \\
\text { period. } \\
\text { Participants commented it was good to have time for reflection } \\
\text { when completing the questionnaire; it provided them with the } \\
\text { opportunity to see both positive and negative aspects of their } \\
\text { general health and wellbeing in the context of their AF diagnosis. } \\
\text { The perceptions of the carer/partner were not necessarily in } \\
\text { agreement with the patient when completing the questionnaire. } \\
\text { The duplication of questions was raised repeatedly, leading to } \\
\text { concern about validity from the patients. }\end{array}$ \\
\hline EQ-5D-5L & $\begin{array}{l}\text { "With this questionnaire I want to write on everything: 'Yes, but this } \\
\text { has nothing to do with my AF'. But how is this going to be } \\
\text { interpreted, what use will it be, and am I screwing this up by filling } \\
\text { this in this way?" } \\
\text { "I have no problem filling it in, but separating AF symptoms from } \\
\text { other health problems is difficult." } \\
\text { "You can come up with different answers within minutes, let alone } \\
\text { today, tomorrow, and the next week" } \\
\text { "I don't know which [symptoms] belong to AF and I don't know } \\
\text { which ones belong to the other problems I have." }\end{array}$ & $\begin{array}{l}\text { Consensus was reached that this questionnaire would be useful } \\
\text { alongside AFEQT in clinical practice to provide more accurate } \\
\text { feedback to healthcare staff on general health. } \\
\text { The brevity of the questionnaire was favoured, but some patients } \\
\text { felt it difficult to sum up their wellbeing for that particular day. } \\
\text { As with the other questionnaires, the issue of separating } \\
\text { comorbidities and the general aging process was problematic. } \\
\text { Transient symptoms created difficulty when completing the } \\
\text { questionnaire. }\end{array}$ \\
\hline AFEQT & $\begin{array}{l}\text { "The questions asked provided reassurance that my symptoms are } \\
\text { not just about the aging process." } \\
\text { "It makes you realise, it's not you, it's just part of you that the AF is } \\
\text { doing all these to you." } \\
\text { "Filling in the questionnaire covering four weeks is difficult. Some } \\
\text { mornings I can get up and feel fine then two hours later I feel yuck." } \\
\text { "How do I answer [whether I am bothered]? Is it that I am not } \\
\text { bothered at all because it's there, or I'm very bothered because it } \\
\text { worries me?" } \\
\text { "Awkward questions for me... is it [due to] my medication or is it } \\
\text { just generally how I am [with my AF]?" }\end{array}$ & $\begin{array}{l}\text { The group were unanimous in their agreement that this } \\
\text { questionnaire was easier to complete than SF36, and it gave the } \\
\text { opportunity for informed choices within their answers. } \\
\text { The scale of being "bothered" created difficulty with participants } \\
\text { being unsure how to interpret their anxieties around their AF } \\
\text { diagnosis and the resultant symptom burden. } \\
\text { AFEQT does not encompass general health, which in some } \\
\text { patients had a bigger impact on overall QoL. } \\
\text { Confusion around symptoms being a result of medications for AF } \\
\text { or other comorbidities (e.g., breathlessness due to asthma). }\end{array}$ \\
\hline
\end{tabular}

2 Separation of emotional from physical wellbeing (for example in SF36) was confusing for many patients who felt that AF impacts were inter-related.

3 AFEQT had the most relevance to AF symptom burden, but attribution to AF or other comorbidities was challenging.

4 There was a difficult balance to strike between content and time taken; for example, comparing the brevity of the EQ-5D-5L questionnaire with the more nuanced but also potentially duplicating questions in SF36.

5 Consensus that collecting both generic and AF-specific QoL would be useful in clinical practice to help clinicians understand the patient's perspective; on balance, the group favoured using EQ-5D-5L with AFEQT.

A summary of relevant quotes from patients relating to each of the 3 QoL tools are presented in Table 2.

\section{Domain 3}

Importance of QoL in the Management of Patients with AF

The major discussion points raised in the focus groups as to whether QoL was an important outcome that clinicians should address were:

1 Improvement in QoL was the most important consideration for this patient group, ahead of mortality or the need for hospital visits.

2 Healthcare professionals in prior consultations often prioritised issues that were important to them rather than the patient, such as deciding on stroke prevention or rhythm control treatments, or on a specific target for heart rate control.

3 A lack of medication review in patients on longstanding treatments contributed to worse QoL and emotional/physical impact from AF. 
Table 3. Importance of QoL for management of AF

\begin{tabular}{|c|c|c|}
\hline Topic & Quote & Comments/Context \\
\hline $\begin{array}{l}\text { Ranking of } \\
\text { outcomes }\end{array}$ & $\begin{array}{l}\text { "If we're talking about AF, [the important factor] is quality of life and to be as } \\
\text { symptom free as we can; to live each day in a way to our maximum potential, } \\
\text { whatever age we are and whatever else we've got, but being able to do life to our } \\
\text { maximum." } \\
\text { "It would be nice for the doctors to ask what is the quality of your life, how is } \\
\text { this affecting the quality of your life." } \\
\text { "I want a longer life and a better quality of life." } \\
\text { "A focus [on QoL] definitely had a positive impact... I don't get out of breath } \\
\text { like I was six months ago." }\end{array}$ & $\begin{array}{l}\text { QoL consistently rated as the most important } \\
\text { outcome in these focus groups. } \\
\text { Patients were less concerned about other } \\
\text { outcomes, such as hospital admissions, which were } \\
\text { usually considered as well-managed by healthcare } \\
\text { professionals. } \\
\text { Specific questions from healthcare professionals } \\
\text { about the impact of AF on QoL was rare. }\end{array}$ \\
\hline $\begin{array}{l}\text { Patient } \\
\text { empowerment }\end{array}$ & $\begin{array}{l}\text { "When you go to bed of a night and you think to yourself 'well, I had a good day, } \\
\text { I enjoyed reading that book,' or 'at least I cleaned the stove, I did it with a little } \\
\text { mop'. It's ridiculous but that's it, you go to bed [and] tomorrow is another day. } \\
\text { If I wake up, I'll see what else I can do." } \\
\text { "I remember standing when I was out of breath, looking in shops and } \\
\text { pretending; I remember a man said to me one day 'You're out of breath' [and I } \\
\text { said] 'No, I've got a bad back'. I was so embarrassed to say I was out of breath... } \\
\text { and it was to do with my heart." } \\
\text { "When you're feeling breathless you step back and stop. [But now] I just push it } \\
\text { that little bit further, and a little bit further, and I felt that has really helped." }\end{array}$ & $\begin{array}{l}\text { Uncertainty around living with AF, and the } \\
\text { variability in day-to-day symptoms increased the } \\
\text { importance of attention on QoL. } \\
\text { Lack of knowledge and fear of the unknown had a } \\
\text { negative impact on patients. } \\
\text { Being provided with broader education (such as } \\
\text { safely increasing exercise to work through } \\
\text { breathlessness) was transformative for } \\
\text { empowering patients. }\end{array}$ \\
\hline $\begin{array}{l}\text { Treatment } \\
\text { expectations }\end{array}$ & $\begin{array}{l}\text { "I don't expect a miracle, but I would like to think that the quality of life I will } \\
\text { have will be better because of [medications I take]." } \\
\text { "I've been on the same medication for ten years; I've come [on this trial] and I've } \\
\text { had a change... looked at thoroughly and properly, and now I feel so much } \\
\text { better." } \\
\text { "I could not have carried on living the life I was living." } \\
\text { "Having been on the trial, it gives you more reassurance that you're dealing with } \\
\text { people who are interested in AF, and I think it makes you more reassured, gives } \\
\text { you more confidence I think. I'm happier." } \\
\text { "I was so tired. But [now] that seems to have gone, so that's better quality of life, } \\
\text { and it's fantastic." } \\
\text { "I want to be treated as a person not just as an AF [patient]; I want the whole } \\
\text { thing treated." } \\
\text { "It helps when you know somebody else is going through it." }\end{array}$ & $\begin{array}{l}\text { Although doctors give medications in AF for } \\
\text { specific purposes (e.g., drugs to control heart rate), } \\
\text { the expectation from patients is that these will } \\
\text { improve QoL. } \\
\text { In patients with longstanding AF, patients felt that } \\
\text { they were left without clinical attention; a } \\
\text { refocused appraisal of medications in the context } \\
\text { of QoL could be helpful at regular reviews. } \\
\text { Prior consultations mostly focused on stroke } \\
\text { prevention and oral anticoagulation. } \\
\text { Being able to discuss the impact of AF with other } \\
\text { patients in a supported group improved } \\
\text { confidence in self-management. }\end{array}$ \\
\hline
\end{tabular}

4 A focus on QoL improvement could engage patients leading to empowerment. The integrated approach in the RATE-AF trial of providing patient education and support was unanimously well received by patients in the focus groups who expressed a sense of confidence and better ability to self-manage their AF.

5 Participation in the focus group itself was beneficial for the patients, who recommended a similar process of peer-support for patients newly receiving treatment for AF, for example, after discharge from hospital.

A summary of relevant quotes from patients are presented in Table 3; in general, these reflect a mixture of the psychosocial and physical impacts of AF, coping mechanisms, and outcomes related to these effects. Whilst this study cannot address whether attention to QoL would improve clinical outcomes, there was consensus from patients that it could improve the care pathway in patients with AF.

\section{Discussion}

This study confirmed that patients with symptomatic permanent AF have considerably worse QoL than the general population or those with a longstanding illness. In focus groups, QoL and symptom management were the predominant concerns of these patients. The wide variation in symptoms experienced, both generic and AFspecific, were underscored by a substantial emotional burden on patients and their families. A reported lack of focus on QoL in prior healthcare consultations contributed to a loss of confidence and a sense of isolation that hindered medical management of their condition. Further, patients felt that the extent of their comorbidities was often neglected. To improve patient wellbeing, management protocols need to consider other conditions such as large-joint arthritis, and not just concentrate on anticoagulation therapies for AF. 
There is increasing recognition that QoL and symptom data should be collected in routine clinical practice for patients with AF [15]; however, measurement of QoL in patients with $\mathrm{AF}$ is associated with a number of methodological challenges. In a systematic review of measurement properties for AF-specific QoL tools, we identified substantial validity concerns for commonly used questionnaires [16]. Hence, many research studies have used generic QoL tools, such as SF36 and EQ-5D-5L. Whilst generic questionnaires allow for comparison across different diseases, they lack attention on the types of symptoms that can impair QoL in patients with AF. In our focus groups, there was consensus amongst patients that a short generic tool, such as EQ-5D-5L, in addition to an AF-specific tool, such as AFEQT, provided the best balance of time taken versus information gained. Although SF36 is comprehensive, and from a technical standpoint appears to cover many of the concepts discussed by patients, there was concern around difficulty to separate emotional and physical impacts from AF, the need for questions to be explained by clinical staff, and duplication in responses. An added advantage of EQ-5D-5L is the use within health economics such as quality-adjusted lifeyear (QALY) analyses. Whichever QoL tool is chosen, our patient groups were clear that they could see a potential benefit in rolling-out these questionnaires into routine clinical practice. Not only would this give patients a framework for their consultations with healthcare professionals, but it would also allow staff to monitor changes in QoL in response to treatment.

Consideration of patient-reported outcomes is now part of international practice guidelines on AF management; clinicians are asked to assess and re-assess QoL, with symptomatic improvement a major treatment objective in patients with AF [9]. Aside from oral anticoagulation for stroke prevention, nearly all other treatments (including rate and rhythm control) are based on evaluation of symptoms. More research on assessment of QoL in clinical practice is clearly warranted to inform clinical decision making and to tailor care to the needs of individual patients. Electronic capture of these data in routine practice could allow for real-time monitoring, flexible and responsive scheduling of hospital appointments, early detection of problems, and prompt intervention to prevent AF-related adverse outcomes [17]. Attention on comorbidities is also an essential component for optimal management of AF. In the RACE III trial, 245 patients with early persistent AF and mild-to-moderate heart failure were randomised to either targeted therapy of underlying conditions or normal care including rhythm control [18]. Comorbidities were better treated in the intervention group and recurrence of AF was lower (75\% of all patients were in sinus rhythm at 1 year, compared to $63 \%$ in the conventional management group; $p=0.042$ ).

Similarly, integrated treatment programmes that improve patient and healthcare staff education, along with nurse-led and lifestyle interventions, have demonstrated improvements in clinical outcomes. In a randomised trial of 712 patients with AF, integrated care led to better adherence to guidelines [19]. The composite of cardiovascular hospitalisation and cardiovascular death was significantly lower in the integrated care arm, $14.3 \% \mathrm{com}$ pared with $20.8 \%$ with usual care (hazard ratio $0.65 ; 95 \%$ CI $0.45-0.93 ; p=0.017)$. Bringing together patients and their healthcare professionals in order to make shared decisions is a key element in patient empowerment [9], especially in this digital era [20], and has the potential to address the persistently poor outcomes seen in older patients with AF [1]. Randomised trials to clarify the impact of AF education for healthcare professionals are ongoing [21]. As demonstrated in a mixed-methods study of 101 patients and 15 clinicians, a lack of appropriate education also hinders the ability of patients to self-manage their AF [22]. The importance of a good knowledge-base has been studied previously, mostly in the context of anticoagulation for stroke prevention [23]. Our impression is that education on other aspects of care, for example, heart rate control, is often neglected in clinical practice. This is particularly the case for patients with permanent AF, who often receive no other therapy and are, therefore, left without the support that patients with paroxysmal AF typically receive when considered for rhythm control.

An unexpected outcome from the focus groups was the benefit the groups themselves had for individual patients. Having a safe space to talk to other patients led to amelioration of the sense of isolation and lack of knowledge. As with other chronic diseases, many of the impacts of AF are psychosocial in nature, and so better adaptation can be a powerful tool (a clear, cross-cutting theme across the domains we investigated). More widespread use of patient support groups within secondary care could have profound benefit for patients and lead to reductions in healthcare utilisation. For example, in hospitalised patients, accredited information could be provided to all patients before, during, and after discharge, along with details of a national or local patient organisation for information and emotional support. Local patient support groups are run by charities such as the Arrhythmia Alliance and AF Association (https://www.heartrhythmalliance.org/), who also moderate online forums with thou- 
sands of members, organise Patient Educational Days, and provide dedicated helplines. Close partnership with these organisations has the potential to support patients and their carers, and further enhance health-related QoL in those with $\mathrm{AF}$ [24].

\section{Strengths and Limitations}

All included patients had permanent AF with symptom-related impairment of daily life at baseline (NYHA class II or above); hence the results presented reflect this patient group. The focus groups took place after control of heart rate and symptoms to better represent the broader community with managed permanent AF. We are limited by the number of patients involved and the need to provide depth over breadth of concepts. Greater numbers within each focus group would have limited discussion, and hence each meeting was restricted to $10 \mathrm{pa}-$ tients. We divided the sessions into two segments to avoid overloading the participants. Meetings were of sufficient duration to achieve saturation within each domain, and they were undertaken within a few weeks of each other to minimise any change over time. All meetings were scheduled in a comfortable and secluded area of the hospital research unit, well known to the patients to limit anxiety. Our analytical methodology used the broad concept of thematic analysis, with a pragmatic approach to reflect that patient and public representatives were leading the focus groups, coding transcripts, and providing data analysis. This provided a unique insight into patient views at many levels. Although the included patients were typical of those with permanent AF and symptom-related impairment of daily life treated in routine clinical practice, we cannot exclude distinct themes arising within patients that agreed to contribute to the focus groups. Those that participated may place a different value on the importance and subsequent assessment of QoL. However, the main discussion points raised in this research were similar in both of the randomised treatment arms, which underwent separate focus group meetings. Our findings would not necessarily apply to AF patients of other ethnic backgrounds, as there are known differences in the presentation and outcomes of AF amongst different racial groups [25].

\section{Conclusion}

Assessing and measuring improvement in QoL and symptoms is fundamental to better management of patients with permanent AF, who suffer from a substantial reduction in their physical wellbeing. The impact of comorbidities is poorly appreciated, with considerable variability in QoL requiring both generic and AF-specific assessment. Broader education is required beyond what is typically given around the prevention of stroke. More widespread use of questionnaires and peer support could have benefits in patients with AF seen in routine clinical practice, enabling care to be tailored to their individual needs.

\section{Acknowledgments}

We would like to thank other members of the RATE-AF team, in addition to the independent members of the trial oversight committees and Jonathan Mathers (Qualitative and Mixed Methods Applied Research, University of Birmingham). We are indebted to the patients and their families who dedicated their time to take part in this NHS research.

\section{Statement of Ethics}

This study was approved by the East Midlands - Derby Research Ethics Committee (16/EM/0178) and the UK Health Research Authority (IRAS project ID: 191437). Audio recordings of the meetings were made with the consent of all participants.

\section{Conflict of Interest Statement}

None of the authors report any conflicts of interest. All authors have completed the ICMJE uniform disclosure form (www.icmje. org/coi_disclosure.pdf) and declare:

D.K. reports grants from the National Institute of Health Research (NIHR CDF-2015-08-074 and NIHR HTA-130280), the British Heart Foundation (PG/17/55/33087 and AA/18/2/34218), EU/EFPIA Innovative Medicines Initiative (BigData@Heart 116074)and IRCCS San Raffaele/Menarini and Amomed (Betablockers in Heart Failure Collaborative Group NCT0083244); in addition to personal fees from Bayer (Advisory Board), AtriCure (Speaker fees), Amomed (Advisory Board), and Myokardia (Advisory Board), all outside the submitted work. M.J.C. receives funding from the NIHR Birmingham Biomedical Research Centre, the NIHR Surgical Reconstruction and Microbiology Research Centre and NIHR ARC West Midlands, Innovate UK (part of UK Research and Innovation), Macmillan Cancer Support, and UCB Pharma; personal fees from Astellas, Takeda, Merck, Daiichi Sankyo, Glaukos, GSK, and the Patient-Centered Outcomes Research Institute (PCORI) outside the submitted work. A.J.C. reports that he has worked with companies that have and are developing anticoagulant drugs, antiarrhythmic therapies, and technology for the management of atrial fibrillation. J.J., M.S., S.H., K.V.B., and T.L. have nothing additional to declare. 


\section{Funding}

The RATE-AF trial and this focus group work was funded by the National Institute for Health Research (NIHR) as part of a Career Development Fellowship to D.K. (CDF-2015-08-074). The Patient and Public Involvement in the design and management of the trial was supported by a grant from the West Midlands NIHR Clinical Research Network. The work is also supported by a British Heart Foundation (BHF) Accelerator Award to the University of Birmingham InstituteofCardiovascularSciences(AA/18/2/34218). The opinions expressed in this paper are those of the authors and do not represent the BHF, NIHR, or the UK Department of Health and Social Care.

\section{Author Contributions}

The Patient and Public Involvement team led the focus groups and all data extraction and thematic analysis (J.J. and M.S.). The concept of the focus groups was originally developed by D.K. (Chief Investigator for the RATE-AF trial) and M.J.C. (expert in patient-reported outcomes). The manuscript was drafted by J.J., M.S., K.V.B. and D.K., and all authors contributed to revision and editing for intellectual content.

\section{References}

1 Lane DA, Skjøth F, Lip GY, Larsen TB, Kotecha $\mathrm{D}$. Temporal trends in incidence, prevalence, and mortality of atrial fibrillation in primary care. J Am Heart Assoc. 2017 Apr; 6(5):e005155.

2 Dorian P, Jung W, Newman D, Paquette M, Wood K, Ayers GM, et al. The impairment of health-related quality of life in patients with intermittent atrial fibrillation: implications for the assessment of investigational therapy. J Am Coll Cardiol. 2000 Oct;36(4):1303-9.

3 Son YJ, Baek KH, Lee SJ, Seo EJ. Health-related quality of life and associated factors in patients with atrial fibrillation: an integrative literature review. Int $J$ Environ Res Public Health. 2019 Aug;16(17):16.

4 Thrall G, Lane D, Carroll D, Lip GY. Quality of life in patients with atrial fibrillation: a systematic review. Am J Med. 2006 May;119(5): 448.e1-19.

5 Krisai P, Blum S, Aeschbacher S, Beer JH, Moschovitis G, Witassek F, et al.; Swiss-AF study investigators. Associations of symptoms and quality of life with outcomes in patients with atrial fibrillation. Heart. 2020 May;heartjnl-2019-316314.

6 Witassek F, Springer A, Adam L, Aeschbacher S, Beer JH, Blum S, et al.; Swiss-AF study investigators. Health-related quality of life in patients with atrial fibrillation: the role of symptoms, comorbidities, and the type of atrial fibrillation. PLoS One. 2019 Dec; 14(12):e0226730.

7 Kotecha D, Calvert M, Deeks JJ, Griffith M, Kirchhof P, Lip GY, et al. A review of rate control in atrial fibrillation, and the rationale and protocol for the RATE-AF trial. BMJ Open. 2017 Jul;7(7):e015099.

8 Kotecha D, Bunting KV, Gill SK, Mehta S, Stanbury M, Jones J, et al.; RATE-AF investigators. Heart rate control for permanent atrial fibrillation: a randomised trial comparing digoxin and beta-blockers (RATE-AF). European Society of Cardiology Congress Late Breaking Hotline; 2020 [cited 2020 August 29]. Available from: https://programme.es-
cardio.org/ESC2020/Channels-by-Topic/ 31184-late-breaking-science-in-atrial-fibrillation-1?r=/ESC2020/Full-Programme?s\%3 D\%24expression\%3DRATE-AF.

9 Kirchhof P, Benussi S, Kotecha D, Ahlsson A, Atar D, Casadei B, et al.; ESC Scientific Document Group. 2016 ESC Guidelines for the management of atrial fibrillation developed in collaboration with EACTS. Eur Heart J. 2016 Oct;37(38):2893-962.

10 Spertus J, Dorian P, Bubien R, Lewis S, Godejohn D, Reynolds MR, et al. Development and validation of the Atrial Fibrillation Effect on QualiTy-of-Life (AFEQT) Questionnaire in patients with atrial fibrillation. Circ Arrhythm Electrophysiol. 2011 Feb;4(1):15-25.

11 Herdman M, Gudex C, Lloyd A, Janssen M, Kind P, Parkin D, et al. Development and preliminary testing of the new five-level version of EQ-5D (EQ-5D-5L). Qual Life Res. 2011 Dec;20(10):1727-36.

12 Ware JE Jr, Gandek B. Overview of the SF-36 Health Survey and the International Quality of Life Assessment (IQOLA) Project. J Clin Epidemiol. 1998 Nov;51(11):903-12.

13 Jenkinson C, Stewart-Brown S, Petersen S, Paice C. Assessment of the SF-36 version 2 in the United Kingdom. J Epidemiol Community Health. 1999 Jan;53(1):46-50.

14 Braun V, Clarke V. Using thematic analysis in psychology. Qual Res Psychol. 2006;3(2):77101.

15 Kirchhof P, Breithardt G, Bax J, Benninger G, Blomstrom-Lundqvist C, Boriani G, et al. A roadmap to improve the quality of atrial fibrillation management: proceedings from the fifth Atrial Fibrillation Network/European Heart Rhythm Association consensus conference. Europace. 2016 Jan;18(1):3750.

16 Kotecha D, Ahmed A, Calvert M, Lencioni M, Terwee CB, Lane DA. Patient-reported outcomes for quality of life assessment in atrial fibrillation: A systematic review of measurement properties. PLoS One. 2016 Nov; 11(11):e0165790.
17 Calvert M, Kyte D, Price G, Valderas JM, Hjollund NH. Maximising the impact of patient reported outcome assessment for patients and society. BMJ. 2019 Jan;364:k5267.

18 Rienstra M, Hobbelt AH, Alings M, Tijssen JG, Smit MD, Brügemann J, et al.; RACE 3 Investigators. Targeted therapy of underlying conditions improves sinus rhythm maintenance in patients with persistent atrial fibrillation: results of the RACE 3 trial. Eur Heart J. 2018 Aug;39(32):2987-96.

19 Hendriks JM, de Wit R, Crijns HJ, Vrijhoef HJ, Prins MH, Pisters R, et al. Nurse-led care vs. usual care for patients with atrial fibrillation: results of a randomized trial of integrated chronic care vs. routine clinical care in ambulatory patients with atrial fibrillation. Eur Heart J. 2012 Nov;33(21):2692-9.

20 Rosselló X, Stanbury M, Beeri R, Kirchhof P, Casadei B, Kotecha D. Digital learning and the future cardiologist. Eur Heart J. 2019 Feb; 40(6):499-501.

21 Bunting KV, Van Gelder IC, Kotecha D. STEEER-AF: a cluster-randomized education trial from the ESC. Eur Heart J. 2020 Jun; 41(21):1952-4.

22 Rush KL, Burton L, Van Der Merwe F, Hatt L, Galloway C. Atrial fibrillation care in rural communities: a mixed methods study of physician and patient perspectives. BMC Fam Pract. 2019 Oct;20(1):144.

23 Mas Dalmau G, Sant Arderiu E, Enfedaque Montes MB, Solà I, Pequeño Saco S, Alonso Coello P. Patients' and physicians' perceptions and attitudes about oral anticoagulation and atrial fibrillation: a qualitative systematic review. BMC Fam Pract. 2017 Jan;18(1):3.

24 Lobban TC, Camm AJ. Patient associations as stakeholders: a valuable partner for facilitating access to therapy. Europace. 2011 May;13 Suppl 2:ii21-4.

25 Ugowe FE, Jackson LR 2nd, Thomas KL. Racial and ethnic differences in the prevalence, management, and outcomes in patients with atrial fibrillation: A systematic review. Heart Rhythm. 2018 Sep;15(9):1337-45. 